\title{
Turning the page on a new chapter
}

\author{
John M Conly MD, Editor-in-Chief
}

I n 1990, a new peer-reviewed journal was launched to focus on infectious diseases from a uniquely Canadian perspective. Initially coined The Canadian Journal of Infectious Diseases and renamed in May 2004 to The Canadian Journal of Infectious Diseases and Medical Microbiology to reflect its broader mandate, it is the official journal of the Association of Medical Microbiology and Infectious Diseases (AMMI) Canada. It took its place in the annals of history with its inaugural issue under the newly appointed Editor-in-Chief, Dr Lindsay Nicolle, of the University of Manitoba (Winnipeg, Manitoba). It has earned its position as a focal point for infectious diseases and medical microbiology in Canada over the first two decades of its publication through the continuous efforts of the Editor-in-Chief, Associate Editor-in-Chief, Associate and Section Editors, the Editorial Board and the publisher, Pulsus Group Inc, as outlined in the past issue (1). Indeed, the readership extends well beyond the disciplines of infectious diseases and microbiology, and has earned a loyal following throughout the broader health care community in Canada.

We are deeply indebted to these early 'pioneers' of the Journal for bringing us forward to this point in time. It is worthwhile to remind the readership of the determination, courage and perseverance of Dr Nicolle, the Editors and the staff of Pulsus Group Inc for bringing us forward to where we are today. Breaking a new trail through a harsh new landscape is much more difficult than travelling the well-trodden path. The Journal has been indexed in EMBASE/Excerpta Medica and Current Contents since 1994, and PubMed (National Library of Medicine, National Institutes of Health [USA]), from 2000 onwards, and is recognized as the repository of scientific articles and editorials that are both unique and relevant to the Canadian perspective of infectious diseases and microbiology.
With this issue, the page is turned on a new chapter in the annals of the history of the Journal. With my appointment as new Editor-in-Chief of the Journal beginning January 1, 2009, it is with great humility that I look back at the work that has been accomplished to date, bringing the Journal to its present state of success. The task that lies ahead is made that much easier by the solid foundation, organization and work ethic that has been laid by Dr Nicolle, Dr Embree and the other Associate and Section Editors. In the present issue, two new Section Editors are being introduced for the Adult Infectious Disease Notes and some of the terms of other Associate and Section Editors may be renewed or come to a close in the ensuing issues. It can be anticipated that other Associate or Section Editors may be appointed in the future as new directions are plotted for the Journal. In addition, this issue marks the introduction of 'online' only publishing of articles, which will increase our publication capacity.

The future of the Journal has both opportunities and challenges in the current global fiscal environment in which we exist today. The fiscal pressures that global economies are currently facing are unprecedented since the Great Depression of the 1930s. Declining pharmaceutical and industrial revenues, declining value of endowments and other monetary funds, combined with a depressed retail market, are realities that many industries are facing. Nevertheless, with the new Webenabled age in which we find ourselves, the ever-expanding repertoire and depth of search engines, the appreciation of making knowledge available in the public domain, and the initiation and expansion of open-access journals, the opportunities for the Journal to forge bold new trails through yet uncharted landscapes holds great promise.

\section{REFERENCE}

1. Nicolle LE. An appreciation. Can J Infect Dis Med Microbiol 2008;19:435.

Department of Medicine, University of Calgary, Calgary, Alberta

Correspondence: Dr John M Conly, Department of Medicine, University of Calgary, \#930, 9th Floor - Foothills Medical Centre North Tower,

1403 - 29th Street Northwest, Calgary, Alberta T2N 2T9. Telephone 403-944-8222, fax 403-944-1095, e-mail jconly@ucalgary.ca

Received and accepted for publication March 2, 2009 


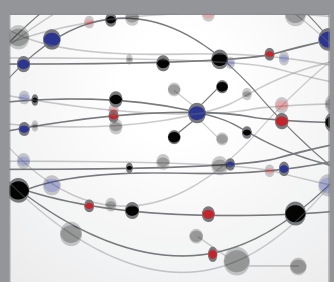

The Scientific World Journal
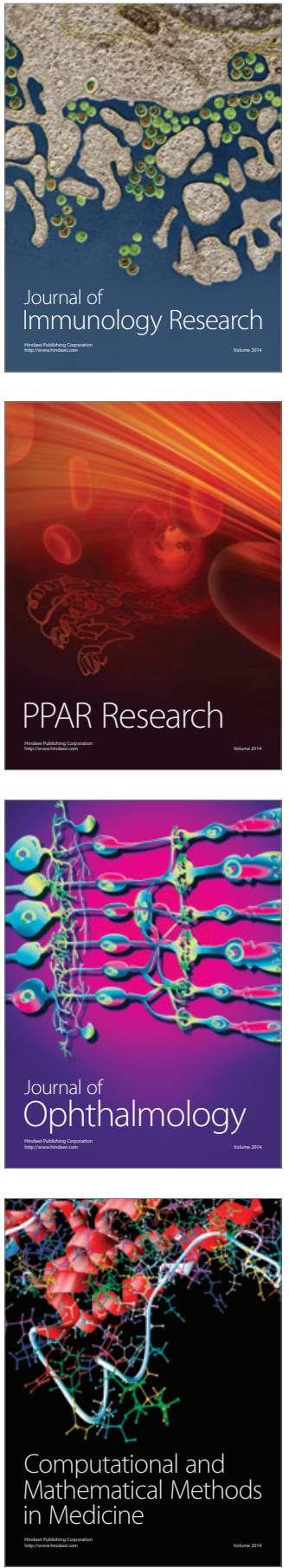

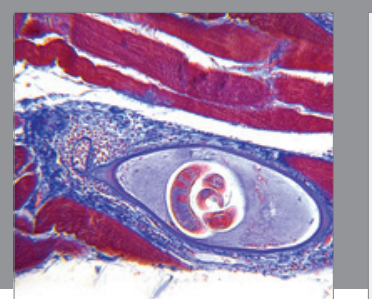

Gastroenterology Research and Practice

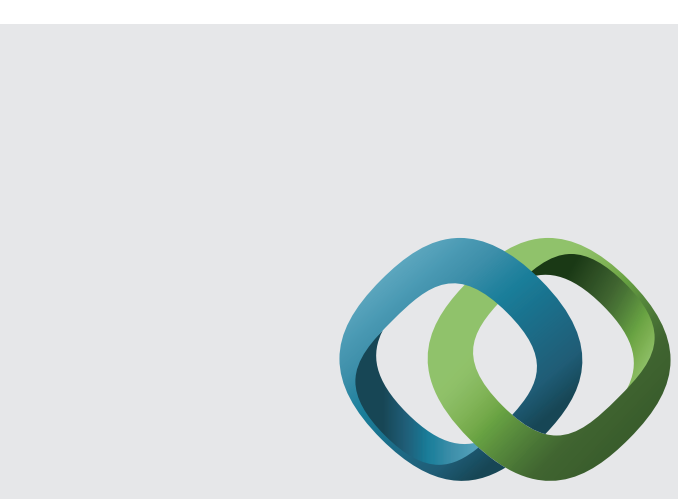

\section{Hindawi}

Submit your manuscripts at

http://www.hindawi.com
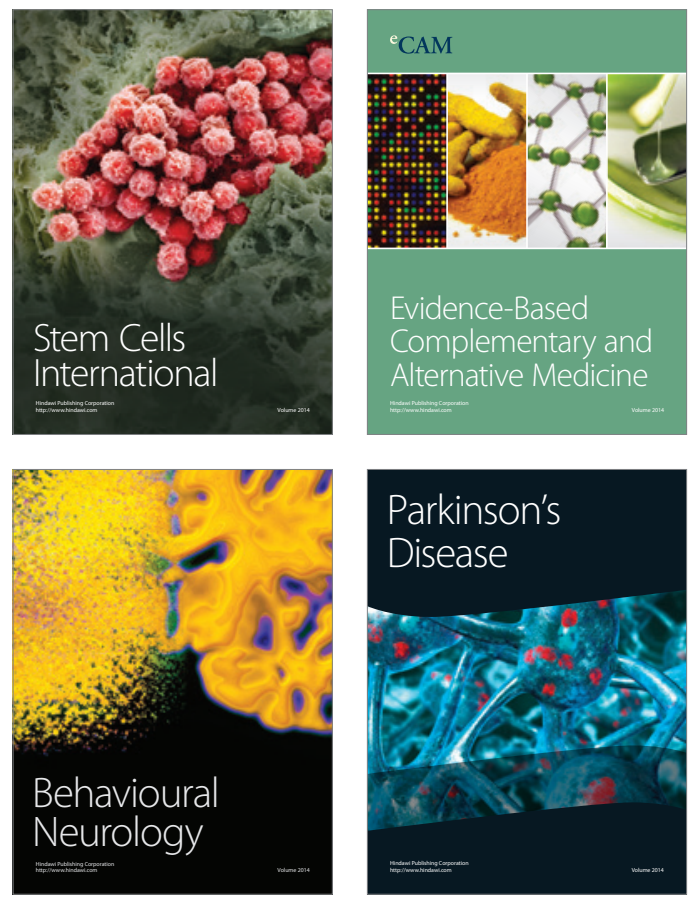
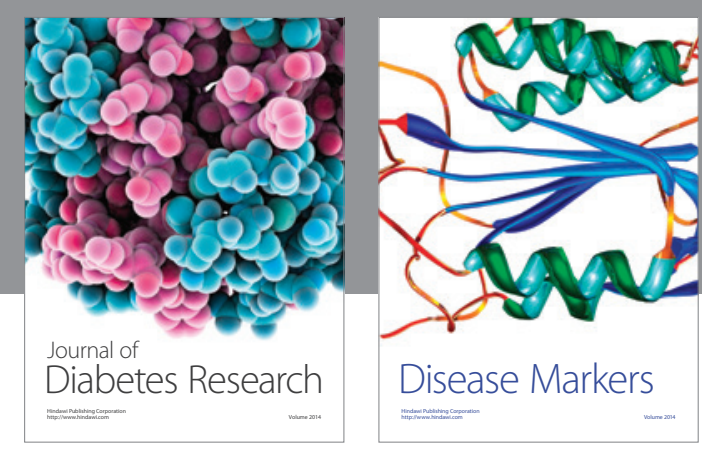

Disease Markers
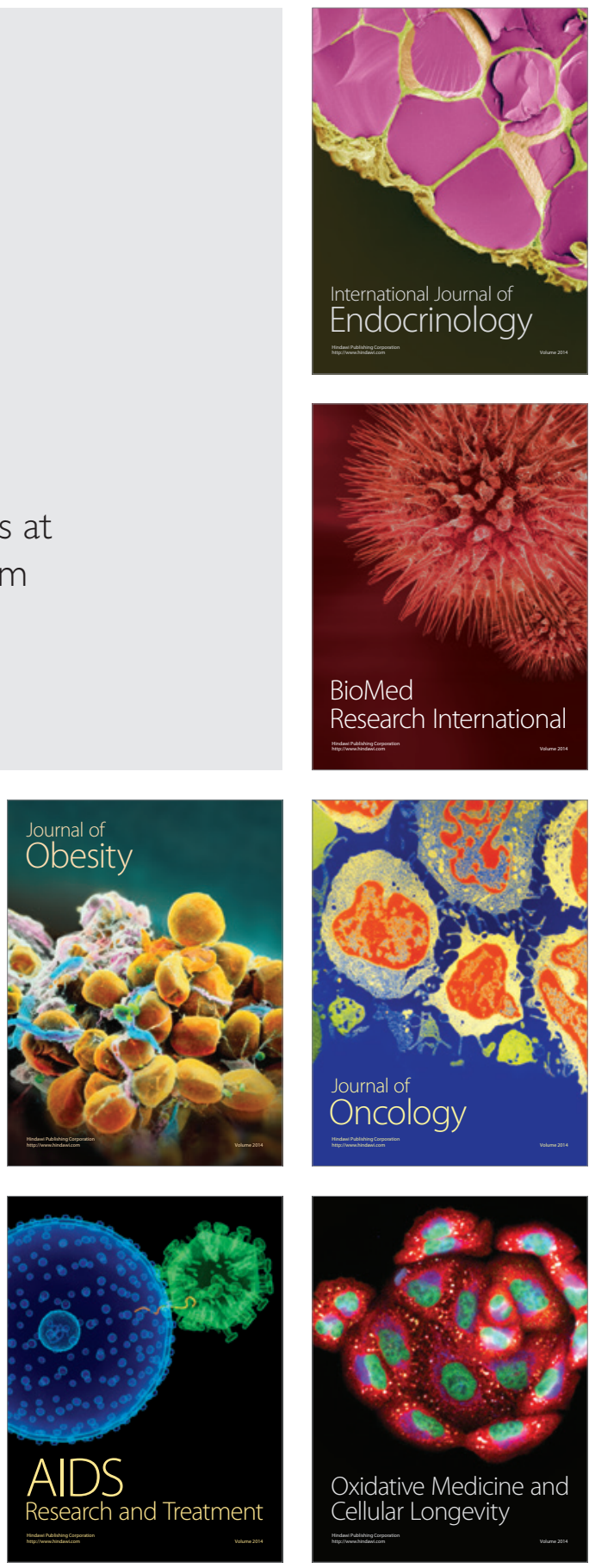